\title{
A didatização de gêneros multimodais: práticas de leitura das histórias em quadrinhos em livros didáticos de língua portuguesa
}

The didatização of multimodal genres: reading practices in comic books in Portuguese language textbooks

Josiane Brunetti, CANI (UFMG) ${ }^{1}$

\section{RESUMO}

O objetivo deste estudo é identificar a abordagem do gênero história em quadrinhos nos livros didáticos de língua portuguesa quanto a aspectos gramaticais, críticos, ilustrativos e, principalmente, semióticos. Tal proposta encontra relevância acadêmica e social na multimodalidade, considerando uma sociedade que requer cada vez mais uma competência comunicativa multissemiótica. Os pressupostos aplicados à análise emergem da teoria cognitiva de aprendizagem multimodal, desenvolvida por Richard Mayer, e do discurso da história em quadrinhos, abordado por Sônia Luyten. Por meio de pesquisa documental e qualitativa, este estudo tem como corpus livros do nono ano do ensino fundamental, inscritos no Programa Nacional do Livro Didático do triênio 2014-2016. Os resultados apontam que, embora a inclusão desse gênero textual nos livros didáticos se faça de maneira significativa, a exploração dos recursos multimodais ainda é incipiente, porquanto as histórias em quadrinhos são utilizadas significativamente como pretexto para análise gramatical.

Palavras-Chave: Ensino, história em quadrinhos, livros didáticos, multimodalidade.

\section{ABSTRACT}

The aim of this study is to identify the approach of the comic book genre in textbooks of Portuguese language as grammatical, critical aspects, illustrative and, especially, semiotic. Such a proposal is academic and social relevance in multimodality, whereas a society that increasingly requires a communicative competence multissemiótica. The assumptions applied to the analysis of cognitive theory emerge multimodal learning, developed by Richard Mayer, and the speech of the comic strip, approached by Sonia Luyten. Through documentary and qualitative research, this study corpus books the ninth grade of elementary school, enrolled in the National Textbook Program the term 2014-2016. The results show that, although the inclusion of this text in textbooks play significantly, the exploitation of the multimodal features is still incipient, as the comics are used significantly as pretext for grammatical analysis.

Keywords: Teaching, comics, textbooks, multimodality.

\footnotetext{
${ }^{1}$ Universidade Federal de Minas Gerais, Belo Horizonte, Minas Gerais, Brasil. Programa de Pós-graduação em Estudos Linguísticos (Poslin); ORCID: http://orcid.org/0000-0001-6560-484X; email: josicani@gmail.com.
} 


\section{Introdução}

Nas duas últimas décadas, as formas de comunicação se fortaleceram expressivamente com o uso das tecnologias digitais. Inseridos por diferentes materializações no cotidiano das pessoas, os textos passaram a funcionar de forma mais intensa pelo viés híbrido: mesclam palavras, símbolos, imagens, sons, vídeos etc., sendo constituídos por uma infinidade de recursos semióticos, modificando, inclusive, nossa forma de perceber o mundo. Por essas razões, trazer para o espaço escolar a discussão sobre a combinação desses recursos significa promover aprendizagens que potencializam a capacidade de processar com propriedade as mais diversas linguagens presentes na vida.

Pesquisas, como as de Almeida (2008), Dionísio (2011), Motta-Roth e Nascimento (2009), Nascimento, Bezerra e Heberle (2011), Rojo (2004), Rojo e Barbosa (2015), Santos (2015) e Silva (2015), discutem a forte presença da multimodalidade na configuração dos gêneros textuais, bem como a importância de desenvolver práticas eficazes para a análise e produção desses textos. Tais estudos reafirmam a premissa fundamental de que não existem textos monossemióticos ou monomodais, considerando que mesmo os escritos se valem de recursos visuais como, por exemplo, a formatação e a tipografia (NASCIMENTO; BEZERRA; HEBERLE, 2011), o que implica a importância do letramento visual para sua interpretação (BAMFORD, 2003; MESSARIS, 1994; STOKES, 2002).

No contexto educacional, a reflexão sobre grande parte desses textos não pode desconsiderar o principal material utilizado pelos professores: os livros didáticos (LD). Embora estes materiais apresentem projetos gráficos compostos de textos multimodais, representando a intenção de aproximar a escola aos gêneros dotados de recursos semióticos em diferentes ambientes, é preciso verificar como a proposta de leitura de textos nesse suporte tem se configurado, considerando o histórico recorrente do uso de imagens em provas e atividades com as funções de explorações gramaticais ou apenas de ornar o texto escrito ${ }^{2}$.

Algumas pesquisas já se debruçaram sobre o assunto, como a de Sousa et al. (2015), que apresenta uma proposta de trabalho com a leitura das HQs em sala de aula; a de Ogliari (2015), cujo objetivo foi compreender formas e potencialidades na cultura atual que superam o letramento limitado à escrita e privilegiam o letramento visual; e a de Araújo e Santos (2014), que analisa modos de empregar ferramentas digitais de produção de HQs para desenvolver as capacidades de linguagem dos alunos. Reconhecendo, pois, a importância dos estudos de gêneros textuais multimodais em sala de aula, nosso objetivo é identificar as abordagens das histórias em quadrinhos (HQs) propostas nos LD de língua portuguesa dos anos finais do ensino fundamental. $\mathrm{O}$ forte apelo visual e linguístico das HQs, naturalmente cômico, tem seduzido crianças e adultos por muito tempo, mesmo após sua materialização em suportes diferentes, pois o que antes buscávamos numa banquinha de revistas, numa exposição colorida das mais diversas HQs, hoje podemos encontrar também no meio virtual.

\footnotetext{
${ }^{2}$ Ramos (2010) destaca o uso das HQs em provas de vestibular e no Exame Nacional do Ensino Médio (Enem), dentre outras situações.
} 
A discussão em torno de valor pedagógico desse gênero já foi palco para gerações que apontavam seu uso inadequado. Em 1954, o livro do psiquiatra alemão Frederic Wertham (2005), Seduction of the innocent, assinalava a nona arte como meio de corromper menores, incitando a violência e a indisciplina escolar (SILVA COSTA; SILVA, 2014, p. 27) ou o consumismo (GUARESCHI, 2001). Por outro lado, a discussão sobre a influência das HQs também se fez presente em discursos que as consideraram recursos de aprendizagem eficazes para crianças (YANG, 2006) e oportunidades para professores envolverem os alunos em análises visuais por múltiplos níveis (BERKOWITZ; PACKER, 2001). Todos esses pressupostos nos levam a refletir sobre o uso de ilustrações nos LD: como a escola se aproxima do texto multimodal? Quais conhecimentos advindos do contato com os gêneros textuais e que significados lhes são atribuídos pelos LD? Quais as funções desempenhadas por imagens nesses recursos, meras ilustrações ou pretextos para análise gramatical?

A leitura de textos multimodais sem o reconhecimento de seus recursos semióticos pode desvalorizar seu potencial comunicacional, desviando a expressividade dialógica e deixando de instigar reflexões e discussões em torno da representação desses textos. Acreditamos que a internet e a multiplicidade de linguagens, que requerem diferentes modos de leitura, devem ser contempladas nos currículos das escolas e jamais antagonizadas como práticas de cultura inapropriadas à aquisição do conhecimento. Como afirma Dionísio (2006), a leitura na sociedade contemporânea demanda uma prática voltada para a multimodalidade, e essa realidade faz parte dos interesses reais dos jovens em relação a suas práticas sociais. É preciso incorporar às aulas de língua portuguesa quaisquer modos de comunicação presentes no mundo contemporâneo, sejam sites, blogs, pinturas, grafites, HQs, infográficos etc.

O enfoque deste estudo não é a apropriação do texto visual pelo professor nem a subsequente recepção do aluno, mas a produção/formulação das discussões com HQs apresentadas nos livros. Por isso, tomaremos como base teórica as concepções de ensino que emergem da teoria cognitiva de aprendizagem multimodal (MAYER, 2009) e o discurso da história dos quadrinhos (LUYTEN, 1985). Por meio de uma abordagem quanti-qualitativa, a análise adota como corpus três livros do nono ano do ensino fundamental, aprovados no Programa Nacional do Livro Didático (PNLD) (BRASIL, 2013) do triênio de 2014 a 2016 : (1) Português: linguagens, de Cereja e Magalhães (2015); (2) Projeto Teláris: português, de Borgatto, Bertin e Marchezi (2012); e (3) Vontade de saber: português, de Alves e Brugnerotto (2012).

Orientado pelas perspectivas mencionadas, inicialmente discutimos o letramento visual e apresentamos o histórico do surgimento das HQs, reconhecendo sua importância como gênero. Em seguida, apontamos o número de HQs inseridas nos livros e sua forma de utilização, com um recorte de cada livro, destacando os aspectos que fundamentam a presença das HQs como recurso pedagógico.

\section{O Letramento Visual}


É muito fácil perceber na comunicação contemporânea que as imagens têm disputado cenários antes ocupados predominantemente por construções verbais, constatação que tem incentivado estudos para investigar tanto as características comuns como as diferenças da integração entre os vários modos semióticos nos eventos de comunicação (CANI, 2019). Fernandes e Almeida (2008, p. 11) apontam que "as imagens produzem e reproduzem relações sociais, comunicam fatos, divulgam eventos e interagem com seus leitores com força semelhante a de um texto formado por palavras”. Segundo Kress e Van Leeuwen (2006 [1996]), as composições visuais, assim como as linguísticas, veiculam significados e, em função disso, necessitam de interpretações específicas quando integradas aos textos multimodais.

O termo multimodalidade, aplicado aos gêneros textuais, foi introduzido por Kress e Van Leeuwen (2006 [1996]), observando que todas as "estruturas visuais produzem significados, assim como as estruturas linguísticas e, portanto, apontam para diferentes interpretações de experiências e diferentes formas de interação social” (KRESS; VAN LEEUWEN, 2006 [1996], p. 2, tradução nossa). Nesse sentido, todo código comunicativo pode ser estudado de forma isolada ou pela junção de suas composições em práticas sociais: as visuais e as verbais.

O conceito de multimodalidade relaciona-se aos estudos da semiótica social que afirma ser a gramática não um conjunto de normas, mas um ponto de partida para explorar a coordenação semântica -, associa a linguagem a um sistema semiótico por meio do qual o ser humano realiza suas experiências (FUZER; CABRAL, 2014, p. 25). Nessa perspectiva, o texto é uma unidade semântica sempre inserida em dois contextos: o situacional e o cultural. Enquanto este se refere aos aspectos culturais envolvidos na produção, aquele se relaciona com todas as informações fora do texto, sejam geográficas, históricas, literárias etc. (HALLIDAY; HASAN, 1989).

Fuzer e Cabral (2014), baseados em Halliday e Hasan (1989), observam que o texto recebe influências do contexto no qual ele está inserido, ou seja, as autoras elucidam acerca da materialização da linguagem por meio do texto, destinado à troca social, de forma indissociável de seu contexto mais amplo de cultura e mais instantâneo de situação.

Figura 1: Texto em contexto

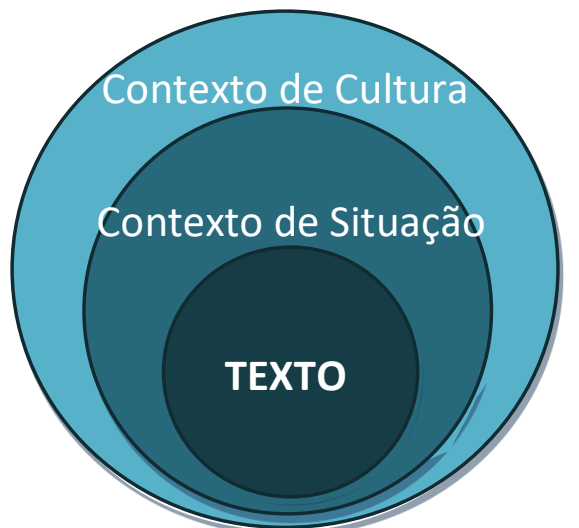

Fonte: Adaptado de Fuzer e Cabral (2014, p. 26). 
Para o contexto de situação, os autores afirmam ser o ambiente em que de fato o texto se encontra; quanto ao contexto de cultura, refere-se a práticas associadas de diferentes países e grupos étnicos, como também a práticas institucionalizadas em grupos sociais, como escola, família, igreja etc. Ao carregar os aspectos de cultura e de situação para o texto, é possível relacionar as interferências ocorridas na produção dos gêneros textuais graças aos recursos semióticos utilizados a partir de contextos históricos, culturais e sociais. Esses recursos, também chamados de "modos”, geram significados, porque são produzidos social e culturalmente, podendo ser incluídos "modos óbvios de comunicação, como a linguagem, gestos, imagens e música, mas, também, os menos óbvios, como: alimentos, roupas e objetos do cotidiano, os quais carregam valor cultural e significado" (VAN LEEUWEN, 2005, p. 2, tradução nossa).

A esses diferentes modos de representar a imagem chamamos de multimodalidade, ou seja, "textos compostos de muitas linguagens (ou modos, ou semioses) e que exigem capacidades e práticas de compreensão e produção de cada uma delas (multiletramentos) para fazer significar” (ROJO, 2012, p. 19). Para a leitura multimodal, tomamos a teoria cognitiva de aprendizagem multimodal (TCAM) de Mayer (2009), que apresenta três hipóteses como processo ativo de aprendizagem:

(a) o homem possui dois canais de processamento de informação: o auditivo e o visual;

(b) cada canal tem uma disposição limitada de acionamento de informações;

(c) os homens se envolvem ativamente na seleção das informações de entrada, organizando-as em representações mentais coerentes e associando-as com outros conhecimentos (MAYER, 2009, p. 63).

O autor, ao discutir a aprendizagem multimodal, apresenta, de sua teoria cognitiva da aprendizagem multimídia, cinco etapas nas quais o aluno precisa se engajar: (1) seleção de palavras relevantes para o processamento na memória de trabalho verbal; (2) seleção de imagens relevantes para o processamento na memória de trabalho visual; (3) organização de palavras selecionadas em um modelo mental verbal; (4) organização de imagens selecionadas em um modelo mental-visual; e (5) integração de representações verbais e visuais (MAYER, 2009).

Mayer traz uma abordagem do conceito de regra que é significativa para o que queremos discutir: o papel do aluno e do material instrucional, que permite ao estudante dar sentido ao seu aprendizado de leitura multimodal (MAYER, 2009, p. 47). Segundo o autor, as pessoas só podem jogar coletivamente após terem dominado as regras de determinado jogo; assim acontece na comunicação, pois os interlocutores só se entendem após dominarem as regras do jogo da linguagem e - mais importante para este trabalho - os inúmeros modos semióticos.

A multimodalidade, então, requer - pelo uso da linguagem em todas as suas aplicações sociais, históricas e culturais - uma construção de sentido que ultrapasse as habilidades de leitura e escrita, 
abarcando também a de ler imagens. É preciso, dentre os multiletramentos ${ }^{3}$, desenvolver o letramento visual para o uso competente da linguagem verbal, das imagens e de outros recursos multimodais que possam construir significados (THE NEW LONDON GROUP, 1996). Muffoletto (2001, p. 4) observa que a definição de letramento visual extrapola a "produção/codificação e leitura/decodificação de experiências visualmente construídas". Conforme o autor, o letramento visual requer a consciência acerca de si próprio e de representações, seja no tempo ou no espaço, que adentra a contextos histórico, político e social, suscitando questionamentos e busca por respostas relacionadas aos múltiplos significados de um momento visual.

Nesse contexto, a linha entre o visual e o verbal tem se tornado cada vez mais tênue, graças a uma invasão de imagens na vida diária que, com seu poder, seja social, ideológico ou cultural, tem fomentado inúmeros estudos (KRESS; VAN LEEUWEN, 1996; MESSARIS, 1994; ROSE, 2001; UNSWORTH, 2001). Por essas razões, para ler hoje é preciso ser letrado visualmente, pois, segundo Oliveira (2006, p. 98),

de coadjuvante nos textos escritos, a representação visual começa a tomar ares de ator principal. O que antes era apenas um adendo ao texto verbal, hoje se mostra um formato instrucional com possibilidades pedagógicas tão eficazes quanto o texto linear, dotado de vida própria e capaz de recriar, representar, reproduzir e transformar a realidade por si, segundo parâmetros comunicativos específicos.

Se pensarmos na pluralidade e riqueza de textos multimodais/visuais que se configuram na vida cotidiana, certamente alguns passariam despercebidos, dada a naturalidade em lidar com muitos recursos que se valem de imagem. Em aplicativos para celulares, por exemplo, os ícones são muito mais representativos para a busca de serviços que a própria escrita. Fonte e Caiado (2014), analisando fragmentos de práticas discursivas extraídas do aplicativo WhatsApp a fim de observar os usos de aspectos multimodais na relação entre texto verbal e visual, apontam que a imagem se destaca de diversas formas: substitui o texto verbal, dá ênfase, antecipa, ilustra e sintetiza as práticas discursivas.

Assim, o letramento visual solicita do leitor (e também do produtor) muito mais que uma simples leitura. Segundo Bamford (2003, p. 1), é preciso (a) atribuir sentido dentro do contexto cultural em que a imagem foi criada; (b) entender a sintaxe, como seu estilo e composição; (c) analisar as técnicas utilizadas em sua produção; (d) avaliar o mérito estético do trabalho; (e) avaliar sua finalidade e audiência; e (f) compreender a sinergia, a interação, a inovação, o impacto afetivo e/ou a "sensação" de uma imagem. A ativação dessas diversas capacidades de leitura visual não pode servir a uma imagem que se coloque apenas como um complemento da linguagem verbal, mas sim como um significativo veículo de comunicação e informação.

\footnotetext{
${ }^{3} \mathrm{O}$ termo "multiletramentos" apresenta-se como uma série de letramentos necessários em meio à globalização, à tecnologia e à diversidade social para práticas com textos multimodais, muito além de textos escritos, com a incorporação de imagens, fotos, gráficos, vídeos, áudios etc. (THE NEW LONDON GROUP, 1996).
} 
Então por que ensinar o letramento visual a nossos alunos? Porque é preciso desenvolver uma percepção e uma metalinguagem visual e linguística que os tornem capazes de "distinguir as mensagens superficiais, glamorosas e pseudo-sofisticadas das reais e valiosas", conforme sugerem Ausburn e Ausburn (1978, p. 288). Messaris (1995) chama a atenção para o fato de que, quando se ensina o espectador das imagens a ser mais crítico em sua leitura, ele se torna também menos suscetível a manipulações gerais de anúncios e de outros contextos.

Nessa linha de raciocínio, acreditamos que desenvolver o letramento visual de nossos alunos implica proporcionar experiências que lhes permitam observar imagens de forma a construir um senso de leitura que os autorize a desvendar os sentidos e interesses por trás delas. Como explicitamos anteriormente, entendemos as HQs como instrumentos valiosos de análise nas salas de aula, se considerada sua riqueza multimodal.

Para alcançar os objetivos deste estudo, iniciamos o percurso com os aspectos que levaram a HQ a ser inserida nos LDs como recurso pedagógico.

\section{O caminho da didatização das Histórias em Quadrinhos}

Os gêneros textuais, orais ou escritos, estruturam-se a partir de propósitos e práticas sociais de seus participantes e são utilizados em conjunto com outros discursos. O New London Group (1996, p. 78) destaca a importância dos significados visuais (imagens, layouts, áudios, espaços ambientais, dentre outros), exemplificando a leitura de comunicação em massa por todos os seus significados, como cassinos, que não possuem relógios ou janelas para remover indicadores de passagem do tempo; ou shoppings, que apresentam logotipos e iluminação em uma arquitetura prazerosa. Os textos são projetados, então, com um leque de escolhas, por diferentes significados. Assim, é praticamente impossível dialogarmos sobre as HQs sem mencionarmos alguns dos aspectos (sociais, históricos, políticos, ideológicos e culturais) inerentes a elas para justificar sua presença nos LDs.

O surgimento das técnicas de reprodução gráfica proporcionou a união entre texto e imagem, fato que permitiu a materialização das HQs. No entanto, foi no final do século XIX que os quadrinhos passaram a ter autonomia, sendo criada uma expressão própria para simbolizá-los: os comics norte-americanos. O Yellow Kid tornou-se a principal atração do jornal New York World e, a partir de 1900, nasceram as histórias humorísticas, com uma variedade de temas em seus enredos, dentre eles, mitologia, fantasia e até ficção científica (CAMPOS; LOMBOLGLIA, 1985, p. 10).

A partir de 1920, surgiram duas correntes para explorar as possibilidades dos quadrinhos: a dos humoristas e a dos intelectuais. A estrutura desse gênero passou a ser influenciada pelo estilo art decó, tornando-se mais elaborada, em virtude de grandes adventos tecnológicos. Mas foi apenas em 1930 que a grande virada se manifestaria, pelo estabelecimento de histórias abordando temas policiais, bélicos, do 
faroeste e outros. Nessa época surgiram Tarzan, de Harold Foster, Flash Gordon, de Alex Raymond e, ao final da década, o Super-Homem, trazendo na sequência uma gama de super-heróis (CAMPOS; LOMBOGLIA, 1985, p. 11-12).

Na década de 1940, concomitantemente à Segunda Guerra Mundial, o gênero passou a representar as lutas contra japoneses e alemães. Em 1950, os quadrinhos iniciaram um período de temas filosóficos e sociopsicológicos. Nessa linha, Charles Schultz criou A turma do Charlie Brown, baseada na filosofia existencialista. Na mesma época, o movimento artístico pop-art se instaurou nessa relação entre pintura e HQs. Em 1960 surgiram as primeiras heroínas, como reflexo de movimentos feministas: Barbarella, do suíço Jean-Claude Forest, Miss Marvel, criada por Roy Thomas e Gene Colan, e a Viúva Negra, de Stan Lee, Don Rico e Don Heck. Somente a partir de 1978, com a exposição de artistas em museus na Europa e nos Estados Unidos, as HQs passaram a ser reconhecidas sob o ponto de vista estético, como manifestação artística (CAMPOS; LOMBOGLIA, 1985, p. 13).

No Brasil, o surgimento da HQ data de 1869, publicada pela revista Vida Fluminense, do Rio de Janeiro, com a história das desventuras de um homem simples do interior: As Aventuras de Nhô Quiim, de Ângelo Agostini, cartunista italiano radicado no Brasil. Em 1905, Manuel Bonfim e Renato de Castro idealizaram a revista $O$ Tico-Tico, com um enredo americano e os personagens Buster Brown e seu cachorro Tige, traduzidos para o português como Chiquinho e Jagunço. O início desse tipo de literatura no país não foi muito criativo, predominando os temas estrangeiros (LACHTERMACHER; MIGUEL, 1985, p. 42).

Não podemos deixar de mencionar, como consolidação das HQs no Brasil, a participação de Maurício de Souza com as histórias da Turma da Mônica. Datada de 1959 e originada das histórias de Bidu e Franjinha, a revista começou a ganhar identidade com as personagens Mônica e Cebolinha, entre 1960 e 1963, levando milhares de crianças e adolescentes a acompanhar as aventuras desses dois, que giravam em torno do conflito entre eles.

No entanto, mesmo com a aceitabilidade de um grande público, no âmbito escolar não foi tão fácil a aceitação dos quadrinhos. Tanto nos LDs quanto em outros materiais pedagógicos, a HQ encontrou sérios obstáculos, tendo sido banida por diversas vezes da sala de aula, pelas mesmas razões já arroladas no histórico anterior. A própria análise realizada para este estudo aponta que as seções destinadas às HQs nos materiais didáticos permanecem ainda em segundo plano. Mendonça, em 2003, apresentou um histórico das HQs que hoje se mantém, quase com idêntico cenário:

no universo dos Livros Didáticos de Português (LDPs), por exemplo, até os anos 70, raramente havia HQs; na década de 90, por outro lado, praticamente todos os LDPs apresentam esse gênero entre os textos selecionados. Ainda assim, as seções destinadas às HQs permanecem sendo as menos "importantes", do tipo "Divirta-se", "Só para ler" ou "texto suplementar". Sendo raríssimos os casos de uma HQ figurar como texto central de unidade didática em um LDP (MENDONÇA, 2003, p. 202-203). 
Segundo Campus e Lomboglia (1985), as HQs, como possibilidades educativas, foram motivo de inquietação entre educadores e sociólogos, pois muitos as consideravam "subliteratura". No entanto, para essas autoras, as HQs, além de propiciarem entretenimento, têm o poder de informar, formar e educar. Segundo Amaral, Rodrigues e Gomes (2013, s.p.), reunidas em pequenos quadros em sequência, por ilimitados períodos históricos, independentes de faixa etária, as HQs apresentam "finalidades que podem ir do entretenimento à crítica social". Reconhecemos, ainda, que as HQs ocupam um espaço significativo nos meios de comunicação, fazendo parte do mundo infantil, como uma das formas de concretizar a alfabetização.

Para Williams (2008), há pelo menos três motivos pelos quais as HQs são potenciais ferramentas de ensino: (1) interesse dos alunos pelo gênero; (2) acessibilidade; e (3) vocabulário simples. A autora ainda destaca que as HQs criam oportunidades para discussões sobre temas significativos em sala de aula, como percepção visual, história da arte, visão crítica da sociedade e humor. Esse gênero auxilia sobremaneira o enriquecimento da leitura, oportunizando a aquisição de informações diversas para o desenvolvimento da aprendizagem, sob inúmeras formas diferentes e interessantes (tiras ou tirinhas, cartuns, mangás, charges, gibis, entre outras). Sua temática varia em função do público-alvo, agradando a crianças e adultos ao abordar aspectos do cotidiano com críticas, política, humor, aventuras, ironia etc.

Segundo a quarta edição da pesquisa Retratos da leitura no Brasil, realizada pelo Instituto PróLivro (FAILLA, 2016), com uma amostra de 5.012 entrevistas domiciliares em 315 municípios de todos os estados e o Distrito Federal, 44\% dos entrevistados afirmaram ler HQs, mesmo que de vez em quando. Além disso, a pesquisa aponta um perfil dos leitores que ratifica a aceitação do gênero por todas as idades. Segundo o levantamento, as HQs são lidas por $29 \%$ das crianças de cinco a dez anos; $21 \%$ dos jovens de onze a treze anos; e 15\% dos adolescentes com catorze a dezessete anos. Entre os leitores adultos, a distribuição por faixa etária é: $11 \%$ das pessoas com dezoito a 24 anos; $12 \%$ com 25 a 29 anos; 10\% com idade entre trinta e 39 anos; $9 \%$ com quarenta a 49 anos; $6 \%$ com cinquenta a 69 anos; e 3\% dos idosos de setenta anos ou mais.

Percebemos, então, que as HQs fazem parte da leitura do brasileiro, não só na infância, mas também na fase adulta, mesmo que a porcentagem de leitores diminua conforme a idade. Sua presença nos espaços educacionais é fato. De acordo com Mendonça (2003), em uma entrevista realizada com alunos do ensino fundamental de escolas públicas e privadas, fica clara a preferência pela leitura das HQs. Considerando o estudo da pesquisadora, é imprescindível dar lugar a esse gênero nas salas de aula - pela riqueza de sua estrutura composicional e, mais ainda, por sua potencialidade de interpretação - como um recurso apropriado, que contribui substancialmente para a formação dos alunos.

Marcuschi (2003) aponta a insistência dos LDs em dar maior destaque a determinado gênero em detrimento de outros, como se houvesse uma hegemonia qualitativa entre as práticas discursivas. $\mathrm{O}$ trabalho com textos necessita de uma atenção igualitária, ampliando a concepção de texto em suas várias 
materializações. Sendo assim, as HQs merecem uma abordagem com a mesma qualidade realizada em outros gêneros, destacando, sobretudo, os aspectos que permitem extrair seu funcionamento composicional, por exemplo, enunciados verbais, imagens, ícones e balões. Como afirma Vergueiro (2004), não há barreiras para o trabalho com HQs:

No caso dos quadrinhos, pode-se dizer que o único limite para seu bom aproveitamento em qualquer sala de aula é a criatividade do professor e sua capacidade de bem utilizálos para atingir seus objetivos. Eles tanto podem ser utilizados para introduzir um tema que será depois desenvolvido por outros meios, para aprofundar um conceito já apresentado, para gerar uma discussão a respeito de um assunto, para ilustrar uma ideia, como uma forma lúdica para tratamento de um tema árido ou como contraposição ao enfoque dado por outro meio de comunicação (VERGUEIRO, 2004, p. 26).

A habilidade de trabalhar com textos multimodais muitas vezes é implícita, talvez por uma crença de que "os sentidos produzidos por imagens sejam 'transparentes', uma espécie de código universal, cujo aprendizado não é de responsabilidade da escola" (NASCIMENTO, BEZERRA, HEBERLE; 2011, p. 532). No entanto, conforme afirmam os autores citados, o emprego de imagens nos textos não pode ser trabalhado à margem de outros gêneros, ainda mais quando há relações sociais, políticas e históricas embasadas pelos comunicados multimodais. Ou seja, a seleção e a organização dos elementos semióticos para a construção do significado incluem a compreensão e o controle competente de todas as suas formas representativas.

Segundo Cope e Kalantzis (2009), a partir de 1990, houve uma transformação da linguagem com a junção de diferentes arquiteturas textuais, indefinindo os limites e as sobreposições de escrita, ícones e imagens. Dionísio (2011, p. 139) defende que, se os processos sociais são fenômenos multimodais, consequentemente os gêneros discursivos também o são, pois, "quando falamos ou escrevemos um texto, estamos usando no mínimo dois modos de representação: palavras e gestos, palavras e entonações, palavras e imagens, palavras e tipografias, palavras e sorrisos, palavras e animações etc.”.

\section{Percurso Metodológico}

Pautamos nosso estudo em uma pesquisa documental, de natureza qualitativa, justificada pela visão investigativa sobre o uso dos textos multimodais nos LDs. Com isso, pretendemos perceber como as HQs são abordadas nos LDs no intuito de desenvolver o letramento visual/multimodal. Inicialmente procedemos a uma revisão bibliográfica, localizando pesquisas relacionadas à temática. Em seguida, focamos dois momentos: (a) compreender os recursos semióticos presentes nas HQs, por meio da leitura dos elementos que as constituem; e (b) analisar seus conteúdos, identificando se os LDs cumprem as propostas de leitura multimodal feitas pelo PNLD quando discorre sobre "o trabalho com diferentes 
letramentos (literário, midiático, de divulgação científica, jornalístico, multimodal etc.)” (PNLD, 2014, p. 45, grifo nosso).

Atendendo a essas reflexões, seguimos duas etapas: a pré-análise, que permite o contato com as HQs dos livros selecionados, isto é, possibilita observar as primeiras impressões sobre o corpus; e a segunda etapa, que chamamos de exploração do material, em que coletamos e organizamos os dados, para categorizá-los conforme os critérios delimitados na primeira etapa. Escolhemos três LDs do nono ano do ensino fundamental de língua portuguesa, inscritos no PNLD do triênio de 2014 a 2016. O critério de seleção considerou o fato de que, dentre os doze livros aceitos pelo PNDL, estes três foram escolhidos por 57\% das escolas públicas, ou seja, somam mais da metade dos livros adotados nessas instituições: (1) Português: linguagens (25\%), de Cereja e Magalhães (2015); (2) Projeto Teláris: português (17\%), de Borgatto, Bertin e Marchezi (2012); e (3) Vontade de Saber: português (15\%), de Alves e Brugnerotto (2012).

Para atingir nosso objetivo, identificar as propostas de abordagem das HQs nos LDs de língua portuguesa, estabelecemos categorias para verificar a aplicabilidade do gênero nos diferentes livros analisados. Nossa proposta de fazer uma pré-análise nos levou a observar outras categorias, além da multimodal, embora sua incidência tenha sido insignificante. Assim, foram realizadas análises quantiqualitativas para a frequência na exploração das HQs, representadas pelas seguintes categorias:

1. Para a análise quantitativa - número total de HQs e tipos de exploração: crítica, gramatical, multimodal ou ilustrativa/diversão;

2. Para a análise qualitativa - descrição das principais explorações das HQs, por meio de um recorte de cada livro analisado.

Os caminhos para a análise seguiram alguns parâmetros, a saber:

(1) Para a exploração multimodal verificamos os processos verbais e mentais, como balão de diálogo ou outro recurso que caracterize fala e/ou pensamento; a moldura, o enquadramento das formas, ângulos, cores, contexto, detalhes, profundidade, iluminação e brilho.

(2) Para a exploração crítica tomamos como ponto de partida o que aponta Rojo (2004) sobre as atividades de leitura, destacando o papel do professor de se desvincular de práticas que idolatram o discurso do autor e induzem à repetição e à reprodução de sua fala. Para a autora, a posição crítica do aluno consiste em apresentar interpretações e discursos flexíveis, percebendo vozes em um contexto sociocultural e estimulando a tomada de consciência sobre a situacionalidade do texto e os propósitos do autor. Acreditamos, ainda, na importância de se questionar visões, ideias, preconceitos e paradigmas inseridos nas HQs.

(3) Para a exploração gramatical propusemos uma análise referente à denominação, classificação e sistematização dos eventos linguísticos à luz de Franchi (1988), que propõe um trabalho progressivo de exercícios para que o estudante, por si só e num processo dedutivo, chegue a conclusões gramaticais. 
(4) Para a exploração ilustrativa/diversão observamos o uso de imagens com a intenção apenas de ornamentar o texto escrito ou como leitura lúdica.

\section{A didatização das HQs nos LDs de língua portuguesa}

Os recursos utilizados por textos multimodais demandam inúmeras estratégias para seu uso em sala de aula. Segundo Vergueiro (2004), as HQs podem circular em espaços de apresentação de um assunto ou de debates. Acrescentamos a essas abordagens análises que possam contemplar também os recursos composicionais e discursivos da HQ. Para iniciarmos nossa verificação de como esse gênero é proposto nos livros selecionados, apresentamos a quantidade de HQs e as formas de exploração identificadas no corpus:

Tabela 1: Análise quantitativa das HQs nos LDs

\begin{tabular}{lccccc}
\hline Livros Didáticos & $\begin{array}{c}\text { Uso } \\
\text { Multimodal }\end{array}$ & Uso Crítico & $\begin{array}{c}\text { Uso } \\
\text { Gramatical }\end{array}$ & $\begin{array}{c}\text { Uso } \\
\text { Ilustrativo } \\
\text { /Divertido }\end{array}$ & Total \\
\hline $\begin{array}{l}\text { Português: } \\
\text { linguagens }\end{array}$ & 0 & 2 & 33 & 5 & 40 \\
$\begin{array}{l}\text { Projeto Teláris: } \\
\text { Português }\end{array}$ & 4 & 4 & 52 & 9 & 69 \\
$\begin{array}{l}\text { Vontade de } \\
\text { Saber: português }\end{array}$ & 0 & 3 & 14 & 0 & 17 \\
\hline \multicolumn{1}{c}{ TOTAL } & 4 & 9 & 99 & 14 & $\mathbf{1 2 6}$ \\
\hline
\end{tabular}

Fonte: Dados do autor.

A análise dos dados da Tabela 1 nos permite inferir que os LDs têm utilizado HQs, mas para enfocar regras da gramática normativa tradicional, considerando que, de um total de $126 \mathrm{HQs}, 78,5 \%$ correspondem a esse tipo de abordagem. Importa destacar que uma mesma HQ se enquadrou em mais de um propósito, portanto, os usos multimodal e gramatical, por exemplo, podem se materializar no mesmo material. Ainda assim, as abordagens gramaticais detectadas nos LDs não contemplam as análises críticas propostas neste trabalho, cuja intenção era que o estudo linguístico ocorresse em situações que levassem o aluno a uma análise estruturada do gênero discursivo, partindo de questões fundamentadas em vários aspectos de sua criação (sociais, políticos, culturais). Ao invés disso, o que observamos foi a insistência em nomenclaturas estéreis e análises sintáticas, estudo que se eximiu de explorar os sentidos, as intenções e as relações socioculturais de emprego da língua.

A proposta de uso crítico, inicialmente traçada como categoria, intencionava observar uma análise que transcendesse a mera extração de informações contidas no texto. Mesmo que em alguns momentos tenham sido solicitadas inferências externas, ativando conhecimentos prévios dos alunos, as perguntas 
não orientavam o leitor para reflexões consideradas relevantes, como o fato de o discurso do autor dar voz aos alunos.

É evidente que os LDs podem - e até devem - apresentar as HQs como diversão, principalmente pela origem desse gênero, conforme já mencionado. O problema é que, em relação ao uso crítico das HQs, apenas $10 \%$ das abordagens se aprofundam em seu potencial de texto polifônico, que traz vozes do contexto sociocultural a serem lidas/ouvidas.

Fizemos, por isso, alguns recortes de HQs nos LDs para procedermos a uma análise qualitativa, descrevendo os tipos de exploração dos textos e sugerindo outras abordagens, a partir de nossa fundamentação teórica e dos inúmeros recursos passíveis de identificação e caracterização do gênero. No entanto, é importante observar que esta análise e nossas sugestões não esgotam as possibilidades oferecidas pelos textos escolhidos. Assim, daremos prioridade a alguns aspectos, considerando ser impossível abarcar todos.

A primeira análise é do livro Vontade de saber: português, para o nono ano (ALVES; BRUGNEROTTO, 2012, p. 65). A atividade encontra-se na Unidade 2, na seção “A língua em estudo", com a apresentação das orações subordinadas substantivas. A introdução ao assunto é realizada com uma tirinha, inserida para refletir e conceituar o período composto. A seguir, na subseção "Praticando", a tirinha novamente serve de exploração gramatical.

Figura 2: Análise da Tirinha 1
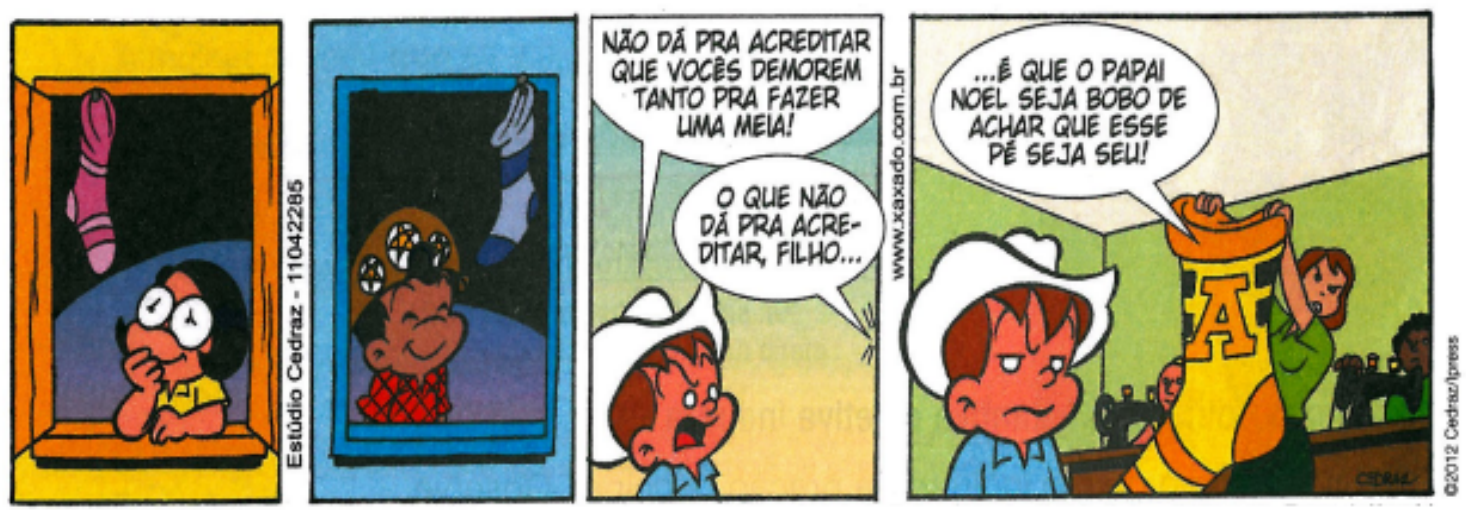

Fonte: Cedraz (2009, p. 65).

As três primeiras perguntas servem para a interpretação do texto: "Na tirinha, Marieta e Xaxado penduraram suas meias nas janelas. Em qual data comemorativa as crianças costumam fazer isso e por quê?"; "Por que a mãe de Arturzinho se mostra incrédula em relação à atitude do filho?"; e "Em sua opinião, por que Arturzinho pediu à mãe que fizesse uma meia de tamanho maior que o seu pé?". A última questão se presta à análise gramatical: “As orações subordinadas substantivas objetivas indiretas devem ser introduzidas por preposição. No entanto, em situações informais de comunicação, é comum que a preposição seja omitida. Na HQ, identifique e transcreva a fala em que isso ocorre.”. 
Retomando Vergueiro (2004), o uso das HQs nos LDs poderia ser enriquecido pela promoção de reflexões sobre vários temas (políticos, religiosos, socioeconômicos, entre outros) que emergem dos discursos. O tom crítico, associado ao humor, por exemplo, é uma excelente estratégia de mediação de temas interessantes. Apropriando-se da empatia que as HQs causam entre os mais diversos leitores, o professor teria na tirinha anterior uma ótima opção para trabalhar um assunto que poderia gerar discussões proveitosas: como ludibriar pessoas. Embora essa reflexão possa estar relacionada à língua do último quadro, não se materializa por meio das questões elaboradas.

Ainda na Tirinha 1, há uma importante sequência de imagens, permitindo a organização da narrativa por meio de elementos icônicos. O design das molduras denota planejamento para dar uma noção de continuidade à história; enquanto os dois primeiros quadros simbolizam a referência à celebração, a inserção do personagem principal no terceiro quadrinho dá início a um novo plano. A partir desse ângulo de visão, a tirinha permitiria explorar as expressões faciais tanto do filho quanto da mãe, pois a semelhança nas curvaturas das sobrancelhas dos dois indica insatisfação com os acontecimentos, embora os interesses sejam diferentes. Ainda mais, haveria a possibilidade de contrastar esse aspecto com os rostos dos primeiros personagens e chamar a atenção para o contraste entre o rosto do filho no terceiro quadro, expressando irritação e impaciência, e no último quadro. As imagens falam por si, principalmente o desenho das bocas.

A primeira questão requer do aluno informações relacionadas a meias, ou seja, é preciso que ele localize uma informação no tempo (no caso, a época do Natal) para relacionar essa peça de roupa ao fato de ganhar presentes na data comemorativa. Prosseguindo, uma discussão mais aprofundada instigaria o desenvolvimento da argumentação e do posicionamento crítico dos alunos diante do tema, no entanto, o que percebemos é uma exploração um tanto indireta nas duas questões posteriores. Observamos, também, que as mesmas questões que levariam a essa postura crítica validam a função das HQs em seu uso mais frequente, o de humor. Assim, dificilmente os alunos atingiriam uma resposta que relacionasse essa característica e o tema identificado, propiciando uma reflexão sobre o enunciado concreto em si, bem como sobre seu argumento de produção.

Na quarta questão, identificamos uma análise gramatical da HQ, pela exploração de uma variedade linguística que apaga o uso da preposição na oralidade. Consideramos que a atividade poderia ser melhor explorada por meio do questionamento de outros aspectos, como: quantas crianças hoje ainda colocam meias e sapatos na janela para ganhar presente de Natal?

É importante perceber que, embora não se configure como um gênero oral, há normalmente uma representação da fala (nos balões) nas HQs, e a mera transcrição de informações não significa que o aluno tenha se apropriado da estrutura da língua e refletido criticamente sobre ela. É preciso que o professor conduza essa apropriação. 
Teixeira (2011) apresenta algumas características essenciais da análise linguística: 1) integração com a leitura e produção de texto; 2) reflexão sobre o uso dos recursos linguísticos, a partir de casos particulares identificados em textos; 3) ênfase nos efeitos de sentido associados aos gêneros; e 4) associação entre habilidades epilinguísticas (reflexão sobre o uso) e metalinguísticas (reflexão voltada para a descrição).

Assim, focalizando questões linguísticas, o Quadro 1 compara os procedimentos de ensino de gramática na tirinha com os da análise linguística proposta neste trabalho:

Quadro 1: Ensino de Gramática e Análise Linguística

\begin{tabular}{|c|c|c|}
\hline \multicolumn{3}{|c|}{ ENSINO DE GRAMÁTICA } \\
\hline & Estratégia utilizada & Habilidade esperada \\
\hline $\begin{array}{l}\text { Objeto de ensino: } \\
\text { Preposição }\end{array}$ & $\begin{array}{l}\text { Exposição da oração retirada } \\
\text { dos quadrinhos para identificar } \\
\text { o uso da preposição nesse tipo } \\
\text { de oração. }\end{array}$ & $\begin{array}{l}\text { Identificar o uso da preposição nas } \\
\text { situações formais de uso, refletindo } \\
\text { sobre a norma culta e sua utilização } \\
\text { pelos falantes contemporâneos do } \\
\text { português. }\end{array}$ \\
\hline \multicolumn{3}{|c|}{ ANÁLISE LINGUÍSTICA } \\
\hline & Estratégia utilizada & Habilidade esperada \\
\hline $\begin{array}{l}\text { Objeto de ensino: } \\
\text { operadores } \\
\text { argumentativos e } \\
\text { organização textual } \\
\text { das sentenças. }\end{array}$ & $\begin{array}{l}\text { Leitura e comparação de } \\
\text { sentenças. } \\
\text { Exercícios de reescrita. } \\
\text { Consulta a manuais, gramáticas } \\
\text { e dicionários para ampliar as } \\
\text { discussões e o próprio } \\
\text { repertório de operadores } \\
\text { argumentativos. }\end{array}$ & $\begin{array}{l}\text { Perceber que as diversas formas de } \\
\text { estruturar períodos por meio de } \\
\text { operadores argumentativos podem } \\
\text { resultar em um texto mais ou } \\
\text { menos coerente. } \\
\text { Refletir sobre a norma culta e a } \\
\text { utilização da língua por falantes } \\
\text { contemporâneos do português. }\end{array}$ \\
\hline
\end{tabular}

Fonte: Elaboração própria a partir de Mendonça (2003, p. 210-214).

A construção da Tirinha 1 envolve uma teia de recursos que possibilitam um desenvolvimento temático de grande relevância informativo-contextual. Por essa razão, o estudo da língua precisa ser constituído por uma tarefa mais fecunda, que não aborde apenas a dimensão funcional, esgotando-se em uma análise de fenômenos linguísticos.

Outra abordagem ilustrativa para nossa reflexão é a do livro Projeto Teláris: português (BORGATTO; BERTIN; MARCHEZI, 2012, p. 153). A seção didática, da qual a tirinha foi retirada, tem como título "Língua: usos e reflexões" e introduz o ensino do período composto por subordinação com sete tirinhas, tomadas como pretexto para apresentação do conteúdo gramatical. Após a explicação, o segmento finaliza com "Hora de organizar o que estudamos", utilizando cinco HQs para a exploração gramatical, como a que segue: 
Figura 3: Análise da Tirinha 2
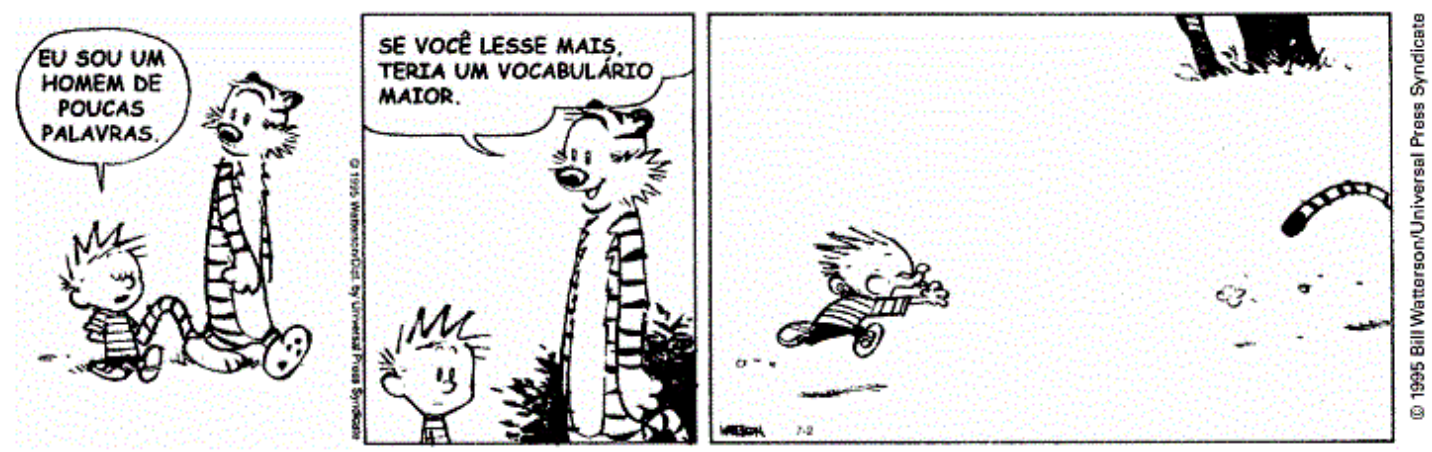

Fonte: Watterson (2005, p. 4).

As perguntas feitas a partir da tirinha servem para introduzir um conteúdo gramatical. A primeira questão solicita que o aluno identifique uma oração: "No primeiro quadrinho, Calvin usa uma frase que é comum, especialmente na fala das pessoas adultas: Eu sou um homem de poucas palavras. A graça da tira está no fato de a personagem Haroldo, no segundo quadrinho, desmascarar a razão de Calvin falar pouco. Releia: Se você lesse mais, teria um vocabulário maior. Responda no caderno: qual é a oração que estabelece a condição para Calvin ser um homem de poucas palavras?".

A segunda questão demanda uma interpretação do aluno: "Ao estabelecer tal condição para a mudança de Calvin, Haroldo interpreta a ideia de 'poucas palavras' como (a) condição de uma pessoa que não gosta de conversar com outras pessoas; (b) condição de pessoa que gosta de ser objetiva ao falar; (c) condição de ser uma pessoa que fala pouco para expressar o que sente; e (d) condição de pessoa que tem preguiça de falar. Embora nosso propósito não seja analisar a questão quanto à interpretação, não encontramos nas opções de resposta para os alunos a indicação na margem, feita para o professor "P: Espera-se que os alunos concluam que o amigo interpreta a expressão 'poucas palavras' como pobreza de vocabulário decorrente de pouca leitura".

Para Neves (2000 apud MENDONÇA 2003, p. 203) “a exploração dos quadrinhos em Livros Didáticos de Português é pobre, limitando-se, na maioria das vezes, à utilização desse gênero como pretexto para exercícios de metalinguagem”. O LD Projeto Teláris: português utiliza-se de grande parte das tirinhas para explicar conteúdos gramaticais. A Tirinha 2, embora apresente a ambiguidade da frase (semântica e sintaxe), serviu apenas como pretexto para estudar a oração subordinada adverbial. A leitura crítica dessa tirinha poderia ser ancorada no argumento de Ramos (2013, p. 108): "ler quadrinhos é ler também sua linguagem". Nesse sentido, a leitura imagética e linguística permitiria construir uma série de inferências com as quais muitas vezes os alunos não estão familiarizados, a partir de informações frequentemente não visíveis na tessitura do texto.

Assim, alguns conhecimentos sobre a história das personagens, como as características que assinalam seu comportamento, seriam necessários aos alunos e permitiriam justificar ações inerentes a Calvin e ao tigre. Calvin é um personagem altivo, arrogante e irônico criado por Bill Watterson. O garoto 
carrega um tigre de pelúcia, Haroldo, sábio e sarcástico, que ganha vida por meio de sua imaginação. $\mathrm{O}$ autor criou um tigre-personagem irônico que usualmente traz reflexões sobre política, cultura, sociedade, relacionamentos e outras realidades do mundo moderno. Por tudo isso, nos quadrinhos anteriores, as inferências exigidas do leitor ultrapassam a superfície do texto. Assim sendo, cabe ao professor supri-las. A frase inicial de Calvin, por exemplo, "Eu sou um homem de poucas palavras" remonta à frase de Willian Shakespeare, "Homens de poucas palavras são os melhores homens", na segunda cena da peça Henrique $V I$. Essa seria uma boa oportunidade para discutir o "peso" das palavras e a objetividade ao falar, ou seja, para observar a importância do que merece ser dito ou calado.

Outro ângulo a ser discutido refere-se à expressão corporal de Calvin, ou seja, ao modo de identificar as reações da personagem. É importante despertar no aluno a diferença entre a linguagem usada nas imagens e a da escrita. Por exemplo, como o leitor descreveria a expressão corporal do garoto nos três quadrinhos? De quais recursos e traços o desenhista se utilizou para mostrar as reações de Calvin? Um detalhe interessante para se discutir é o corte na ação entre os dois primeiros quadrinhos e o último: a imagem no terceiro quadro, sem o uso de estruturas linguísticas, deixa explícito que Calvin se irritara com a fala de Haroldo. O próprio autor da HQ foi "um homem de poucas palavras" no último quadro, em que a ausência de texto escrito não diminuiu o poder de explicitar o aborrecimento de Calvin com Haroldo, ao reagir correndo atrás dele.

Segundo Silva (2001, p. 2-3), o campo da narrativa cinematográfica empresta muitos conceitos às HQs, e um deles se refere à ideia de movimentação. Embora no cinema as imagens estejam em movimento e nas HQs sejam estáticas, alguns traços cinéticos dão a ideia de movimento, conferindo vida aos quadrinhos. A imagem do último quadrinho representa a reação de Calvin diante da fala de Haroldo. É possível observar os traços cinéticos no chão, junto do pé de Calvin, a posição de seus braços e pernas e, principalmente, o desenho de seus cabelos ao vento, assim como o rabo do tigre. Além disso, as nuvenzinhas que demonstram o deslocamento das personagens são proporcionais à velocidade, indicando quem está correndo mais.

Quanto às questões gramaticais, outra observação incide no uso da conjunção condicional contrafactual 4 "se", no enunciado "se você lesse mais...". A exploração de seu valor semântico (ato ilocutório, a intenção do autor) introduz possíveis interpretações, como a de que Calvin não tem o hábito de ler, o que provoca sua expressão facial e sua ação de correr atrás de Haroldo, ato que já carrega a informação. No entanto, a estratégia utilizada no livro desperdiça a oportunidade de uma abordagem mais interpretativa e de uma discussão pertinente. Observamos, também, a representação metonímica, quando Haroldo é ilustrado apenas pelo desenho de seu rabo listrado.

\footnotetext{
${ }^{4}$ Tomamos a distinção feita por Antunes (2010,p. 140) entre as condicionais factuais ou reais e as condicionais contrafactuais ou irreais.
} 
Vale ressaltar que o autor das tiras, sub-repticiamente e usando a ironia, nos ensina que ler é melhorar os conhecimentos sobre a língua, neste caso, o inventário vocabular ("Se você lesse mais, teria um vocabulário maior."). Consideramos que o estudo dessa tira poderia se aprofundar nos aspectos semânticos da língua, por serem construtores do humor, mais interessantes e menos áridos, além de possibilitar a reflexão sobre a vida, os sentidos múltiplos das palavras e das figuras do discurso, como a ironia.

O próximo exemplo a ser analisado, também do nono ano, é do livro Português: linguagens (CEREJA; MAGALHÃES, 2015, p. 210). No primeiro capítulo da Unidade 4, a seção didática “A língua em foco" introduz o conceito de regência verbal e nominal. Após a apresentação do assunto, há uma sequência de atividades que se baseia na Tirinha 3.

Figura 4: Análise da Tirinha 3

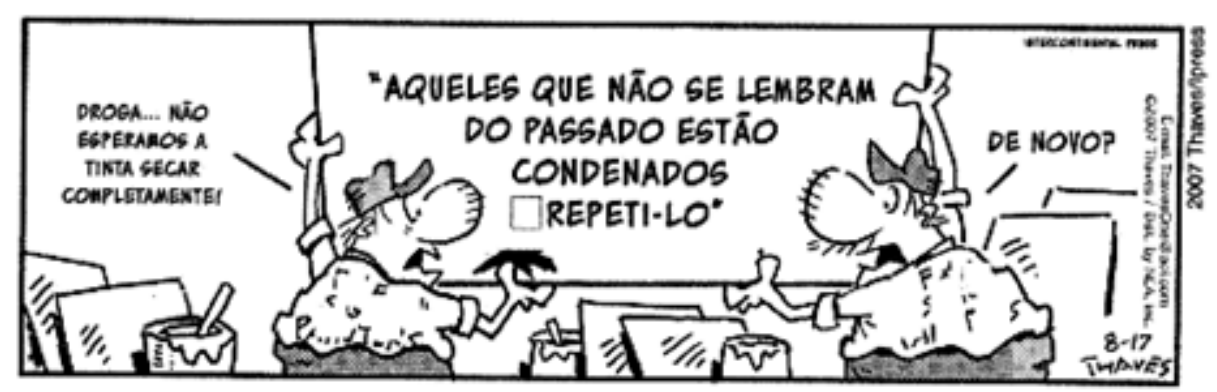

Fonte: Thaves (2010).

A tirinha serve de suporte para quatro questões de análise gramatical: 1) "De acordo com a normapadrão, que preposição completa adequadamente a frase do cartaz da tira: de, em ou a?"; 2) “O verbo lembrar apresenta mais de uma regência, de acordo com a norma-padrão. Observe o emprego que ele tem, quanto à regência, no enunciado do cartaz da tira: a) Esse emprego está de acordo com a normapadrão? Justifique sua resposta; b) reescreva o enunciado do cartaz, empregando a outra regência do verbo lembrar na norma-padrão."; 3 ) "Em que consiste o humor da tira?”; e 4) "Reescreva o texto a seguir, completando-o com a preposição adequada à regência dos verbos e nomes, de acordo com a normapadrão.".

Utilizar HQs apenas para reconhecer a norma padrão da língua - nesse caso da regência, inclusive com nomenclaturas e classificações complexas, sem reflexão ou exploração do verbo "lembrar" -, com exemplos vários e sem considerar outros usos e modalidades orais e escritas, é tornar a aplicação desse gênero irrelevante, disfuncional, em que pese sua riqueza semiótica. É necessário ir muito além disso para justificar a exploração do quadrinho. Nas HQs, as imagens oferecem suporte ao texto escrito, apresentando pistas contextuais que levam à construção do significado da mensagem. Assim, operando como "uma espécie de andaime para o conhecimento" (LUYTEN, 2011, p. 6), os elementos que constituem a linguagem dos quadrinhos vão oportunizando ao leitor exercer o raciocínio. 
A terceira pergunta da atividade ("Em que consiste o humor da tira?") é pelo menos estranha, porque existem teorias que explicam a composição do humor. Talvez a intenção do autor fosse que os alunos explicassem o humor através da língua, das imagens ou das teorias. Tarefa árdua. $\mathrm{O}$ humor emerge do discurso, isto é, do que se posta nas entrelinhas do texto. Esse discurso, "Aqueles que não se lembram do passado estão condenados _ repeti-lo", aponta para a conclusão de que, como não se lembraram de esperar a tinta secar bem, os trabalhadores terão que refazer a placa. $\mathrm{O}$ discurso, obviamente, se sustenta nos enunciados e nas imagens do quadro, que operam em uníssono; e são as opções linguísticas que, em conjunto com as imagens, explicam o humor.

A tira anterior é um claro exemplo de que as HQs possuem poder comunicacional e de exploração pelos LDs de língua portuguesa. Embora a temática presente no quadro possa proporcionar debates e aprendizagens significativas, não há nenhuma referência nesse sentido nas questões apresentadas pelos autores do livro. Alguns recursos e aspectos relevantes para a construção do texto poderiam ter sido abordados. A seleção lexical dos pronomes, por exemplo, permitiria analisar a coesão do texto, caso de “àqueles”, que, por sua natureza dêitica, poderia exigir uma reflexão do leitor sobre referenciação, sobre quem seriam essas pessoas; além de explorar o uso do pronome "o", que assumiu a forma "lo", devido ao verbo terminado em "r", ao retomar anaforicamente a palavra "passado". Tudo isso ajudaria o leitor a se conscientizar sobre o aspecto coesivo do texto.

$\mathrm{Na}$ análise da tirinha identificamos uma abordagem gramatical que leva os usuários do LD a resolverem exercícios estruturais, com a intenção de fixar o conteúdo estudado no capítulo. A análise de estratégias e exercícios propostos, a partir das tiras e quadros, aponta uma abordagem tradicional de interpretação de textos e sugere que as imagens teriam sido introduzidas nos LDs com a intenção de ensinar gramática.

Os resultados deste estudo apontam alguns aspectos que necessitam de cuidado especial ao serem ensinados nas salas de aula. Primeiro, as imagens inseridas nos LDs são apresentadas de forma superficial, sendo estudadas principalmente sob abordagens gramaticais. Outro ponto importante diz respeito à capacitação do professor para lidar com os elementos visuais. É preciso desenvolver as tarefas indicadas pelos materiais criando estratégias que estimulem a leitura das imagens por um viés crítico e de forma mais detalhada, sem o espontaneísmo comum a esse tipo de atividade. Também é fundamental ressaltar a real necessidade de aprofundar essas visões durante o uso de imagens nas escolas, principalmente porque a indústria cultural exige não um espectador passivo, mas alguém em constante reavaliação de suas concepções e escolhas ao lidar com os mais variados tipos de textos.

Embora a proposta deste estudo fosse identificar as abordagens das HQs propostas nos LDs de língua portuguesa, é importante pontuarmos a necessidade de professores que desenvolvam em seus alunos habilidades para a leitura visual, contribuindo para um olhar crítico e cauteloso à imensa variedade de imagens que se encontram dentro e fora das escolas. As imagens são pontes para valores culturais e se 
revestem muitas vezes de metáforas que surgem do meio social, construindo significados nem sempre visíveis a olhos inexperientes. Assim, uma formação na perspectiva do letramento visual permitiria um consumo de imagens não mais neutro, mas, sim, voltado para um processamento de informações adequado à complexidade que elas exigem.

\section{Considerações Finais}

As HQs se configuram como um gênero permeado de inúmeros recursos multimodais, representados por imagens, balões, onomatopeias, palavras, cores, personagens, expressões, entre outros. No entanto, embora apresente essa riqueza de signos para interpretações, sua utilização nos LDs ainda se fortalece por questões de base estruturalista, servindo somente de pretexto para análises interpretativas mecânicas, estudo gramatical ou diversão. Esse aproveitamento ínfimo das HQs em materiais didáticos empobrece e não justifica sua inclusão em tais instrumentos, pois não se dá o devido tratamento às diversas possibilidades de aprendizagem de leitura e compreensão do texto, da escrita, da vida que elas suscitam.

A análise dos exemplos anteriores, retirados dos três LDs que serviram de corpus deste estudo, nos permitiu concluir que semântica, ironia, humor, intencionalidade e outros aspectos importantes para o processo de compreensão e interpretação poderiam ser mais bem perscrutados. Além disso, em nenhum dos livros se trabalhou com a construção e atribuição dos significados aos recursos semióticos como balões, cores, formatos, enfim, elementos característicos desse gênero que podem e devem ser explorados por sua riqueza e versatilidade.

A opção por analisar esse gênero decorreu sobretudo da nossa comprovação da necessidade de discussões sobre a leitura multimodal, posicionando-nos sempre a favor de uma visão que possibilite constatar como os recursos semióticos reproduzem e estabelecem significados por sua própria natureza. Temos a convicção de que o papel do processo de ensino e aprendizagem é contemplar uma análise dos gêneros em todos os seus elementos linguístico-discursivos, o que não permite que nos abstenhamos das discussões multimodais suscitadas pelas imagens. Nesse cenário, o uso das HQs nos LDs de português não se justifica, finalmente, pela insistência na exploração de fenômenos linguísticos sem reflexão pertinente.

Importante lembrarmos que o LD é uma "orientação" para o professor, que pode e deve direcionar seu olhar para além do material, sem aceitá-lo como um instrumento de ensino prescritivo, com perguntas e respostas estéreis. É preciso expandir a leitura a outras possibilidades pedagógicas, além das orientadas pelos LDs, desenvolvendo em seus alunos habilidades e competências visuais que lhes possibilitem perceber a integração de diferentes modos semióticos nos processos comunicativos.

\section{Referências}


ALMEIDA, D. B. L. (Org.). Perspectivas em análise visual: do fotojornalismo ao blog. João Pessoa: Editora Universitária UFPB, 2008.

ALVES, R.; BRUGNEROTTO, T. Vontade de saber: português. São Paulo: FTD, 2012. (Ensino Fundamental, 9).

AMARAL, E. L. S.; RODRIGUES, M. L.; GOMES, N. S. O percurso dos quadrinhos como instrumento para o ensino de língua portuguesa. Web Revista Discursividade, São Paulo, v. 12, n. 1, 2013. (Não paginado).

ANTUNES, I. Análise de textos: fundamentos e práticas. São Paulo: Parábola, 2010.

AUSBURN, L.; AUSBURN, F. Visual literacy: background theory and practice. PLET, Abingdon, v. 15, n. 4, p. 291-297, 1978.

BAMFORD, A. The visual literacy white paper. Uxbridge: Adobe Systems Incorporated, 2003.

Disponível em: $<$ https://www.aperture.org/wp-content/uploads/2013/05/visual-literacy-wp.pdf $>$. Acesso em: 3 ago. 2018.

BERKOWITZ, J.; PACKER, T. Heroes in the classroom: comic books in art education. Art Education, Alexandria, v. 54, n. 6, p. 12-18, 2001.

BORGATTO, A. M. T.; BERTIN, T. C.; MARCHEZI, V. L. C. Projeto Teláris: português. São Paulo: Ática, 2012. (Ensino Fundamental, 6).

BRASIL. Ministério da Educação. Fundo Nacional de Desenvolvimento da Educação. Programa Nacional do Livro Didático. 2013. Disponível em: http://www.fnde.gov.br/programas/programas-dolivro/livro-didatico/guia-do-livro-didatico/item/3773-guia-pnld-2013-\%E2\%80\%93-ensino-

fundamental. Acesso em: 4 de novembro de 2017.

CAMPOS, M. F. H.; LOMBOGLIA, R. HQ: uma manifestação de arte. In: LUYTEN, S. M. B. (Org.). Histórias Em Quadrinhos: leitura crítica. São Paulo: Paulinas, 1985. p. 10-17.

CANI, Josiane Brunetti. Multimodalidade e efeitos de sentido no gênero meme. Periferia, v. 11, n. 2, p. 242-267, 2019.

CEDRAZ, A. Xaxado: 1000 tiras em quadrinhos. Salvador: Cedraz, 2009.

CEREJA, W. R.; MAGALHÃES, T. C. Português: linguagens. São Paulo: Saraiva, 2015. (Ensino Fundamental, 9).

COPE, B.; KALANTZIS, M. A grammar of multimodality. The International Journal of Learning, Flacq, v. 16, n. 4, p. 361-426, 2009.

DIONÍSIO, A. P. Gêneros multimodais e multiletramento. In: KARWOSKI, A. M.; GAYDECZKA, B.; BRITO K. S. (Orgs.). Gêneros textuais: reflexões e ensino. 3. ed. rev. Rio de Janeiro: Nova Fronteira, 2006. p. 137-152.

DIONISIO, A. P. Gêneros textuais e multimodalidade. In: DIONÍSIO, A. P. et al. (Orgs.). Gêneros textuais: reflexões e ensino. São Paulo: Parábola, 2011. p. 137-152.

FAILLA, Z. (Org.). Retratos da leitura no Brasil. São Paulo: Instituto Pró-livro/Imprensa Oficial, 2016. V. 3.

FERNANDES, J. D. C.; ALMEIDA, D. B. L. Revisitando a gramática visual nos cartazes de guerra. In: ALMEIDA, D. B. L. (Org.). Perspectivas em análise visual. João Pessoa: Editora da UFPB, 2008. p. 1131.

FONTE, R.; CAIADO, R. Práticas discursivas multimodais no WhatsApp: uma análise verbo-visual.

Desenredo, Passo Fundo, v. 10, n. 2, p. 475-487, 2014.

FRANCHI, C. Criatividade e gramática. São Paulo: Secretaria de Estado da Educação/Coordenadoria de Estudos e Normas Pedagógicas, 1988.

FUZER, C.; CABRAL, S. R. S. Introdução à gramática sistêmico-funcional em língua portuguesa.

Campinas: Mercado de Letras, 2014.

GUARESCHI, P. A. Comunicação \& poder: a presença e o papel dos meios de comunicação de massa estrangeiros na América Latina. Petrópolis: Vozes, 2001.

HALLIDAY, M. A.; HASAN, R. Language, context, and text: aspects of language in a social-semiotic perspective. New York: Oxford Press, 1989.

KRESS, G.; VAN LEEUWEN, T. Reading images: the grammar of visual design. 2. ed. London:

Routledge, 2006 [1996]. 
LACHTERMACHER, S.; MIGUEL, E. HQ no Brasil: sua história e luta pelo mercado. In: LUYTEN, S. M. B. (Org.). História em quadrinhos: leitura crítica. 2. ed. São Paulo: Paulinas, 1985. p. 41-48. LUYTEN, S M. B. HQ como prática pedagógica. In: crítica. São Paulo: Paulinas, 1985. p. 79-85.

. (Org.). Histórias em quadrinhos: leitura

LUYTEN, S. M. B. História em quadrinhos: um recurso de aprendizagem. Boletim 1, Rio de Janeiro, ano 21, p. 21-26. 2011. (Salto para o Futuro).

MAYER, R. E. Multimedia learning. Cambridge, UK: Cambridge University Press, 2009.

MARCUSCHI, L. A. Compreensão de texto: algumas reflexões. In: DIONÍSIO, A. P.; BEZERRA, M. A. (Orgs.). O livro didático de português: múltiplos olhares. 3. ed. Rio de Janeiro: Lucerna, 2003. p. 3871.

MENDONÇA, M. R. S. Um gênero quadro a quadro: a história em quadrinhos. In: DIONÍSIO, A. P.; MACHADO, A. R.; BEZERRA, M. A. (Orgs). Gêneros textuais e ensino. 2. ed. Rio de Janeiro: Lucerna, 2003. p. 194-207.

MESSARIS, P. Visual literacy: image, mind and reality. San Francisco: Westview, 1994. MESSARIS, P. Visual literacy and visual culture. In: ANNUAL CONFERENCE FOR THE INTERNATIONAL VISUAL LITERACY ASSOCIATION, 26., 1995. Tempe. Proceedings... Tempe: International Visual Literacy Association, 1995. p. 51-56.

MUFFOLETTO, R. An Inquiry into the nature of Uncle Joe's representattion and meaning. Reading Online, Vol. 8, No.4. Disponível em: http://www.readingonline.org/newliteracies/muffoletto/index.html. Acesso em 25 de junho de 2017.

MOTTA-ROTH, D.; NASCIMENTO, F. S. Transitivity in visual grammar: concepts and applications. Linguagem \& Ensino, Pelotas, v. 12, n. 2, p. 319-349, 2009.

NASCIMENTO, R. G.; BEZERRA, F. A. S.; HEBERLE, V. M. Multiletramentos: iniciação à análise de imagens. Linguagem \& Ensino, Pelotas, v. 14, n. 2, p. 529-552, 2011.

OGLIARI, C. L. Letramento e o mundo comics. 2015. 149 f. Dissertação (Mestrado em Engenharia e Gestão do Conhecimento) - Universidade Federal de Santa Catarina, Florianópolis, 2015.

OLIVEIRA, S. Texto visual, estereótipos de gênero e o livro didático de língua estrangeira. Trabalhos em Linguística Aplicada, Campinas, v. 47, n. 1, p. 91-117, 2006.

RAMOS, P. A leitura dos quadrinhos. São Paulo: Contexto, 2010.

RAMOS, P. A leitura oculta: processos de produção de sentido em histórias em quadrinhos. In:

BUNZEN, C.; MENDONÇA, M. (Org.). Múltiplas linguagens para o ensino médio. São Paulo:

Parábola, 2013. p. 103-118.

ROJO, R. Letramento e capacidades de leitura para a cidadania. São Paulo: Secretaria de Estado da Educação/Coordenadoria de Estudos e Normas Pedagógicas, 2004.

ROJO, R. Pedagogia dos multiletramentos. In: ROJO, R.; MOURA, E. Multiletramentos na escola. São Paulo: Parábola, 2012. p. 11-31.

ROJO, R.; BARBOSA, J. P. Hipermodernidade, multiletramentos e gêneros discursivos. São Paulo: Parábola, 2015.

ROSE, G. Visual methodologies: an introduction to the interpretation of visual materials. London: Sage, 2001.

SANTOS, F. C. D. R. Adaptando materiais: um experimento a partir de textos de livros didáticos. In: HEMAIS, B. J. W. (Org.). Gêneros discursivos e multimodalidade: desafios, reflexões e propostas no ensino de inglês. Campinas: Pontes, 2015. p. 191-219.

SILVA, R. C. O livro didático de inglês como um gênero discursivo multimodal promotor de letramentos múltiplos. In: HEMAIS, B. J. W. (Org.). Gêneros discursivos e multimodalidade: desafios, reflexões e propostas no ensino de inglês. Campinas: Pontes, 2015. p. 35-62.

SILVA, N. M. Elementos para a análise das histórias em quadrinhos. In: CONGRESSO BRASILEIRO DA COMUNICAÇÃO, 24, 2001, Campo Grande. Anais... Campo Grande: Intercom, 2001. p. 1-15. Disponível em: http://www.portcom.intercom.org.br/pdfs/145679190592438538598866043670438455063.pdf. Acesso em: 12 de julho de 2017. 
SILVA COSTA, A. B.; SILVA, E. P. Níquel Náusea vai à escola: usos dos quadrinhos em sala de aula. Comunicação \& Educação, São Paulo, v. 20, n. 2, p. 27-38, 2014.

SOUSA, A. M. et al. Histórias em quadrinhos: uma proposta de letramento. Tropos, Rio Branco, v. 1, n. 4, p. 1-10, 2015.

STOKES, S. Visual literacy in teaching and learning: a literature perspective. Eletronic Journal for the Integration of Technology in Education, Pocatello, v. 1, n. 1, p. 10-19, 2002.

TEIXEIRA, C. S. Ensino de gramática e análise linguística. Ecos, Cáceres, v. 11, n. 2, 2011.

THE NEW LONDON GROUP. A pedagogy of multiliteracies: designing social futures. Harvard

Educational Review, Cambridge, MA, v. 66, n. 1, p. 60-93, 1996.

UNSWORTH, L. Teaching multiliteracies across the curriculum: changing contexts of text and image in classroom practice. Buckingham, UK: Open University, 2001.

VAN LEEUWEN, T. Introducing social semiotics. Routledge: Psychology Press, 2005.

VERGUEIRO, W. Uso das HQs no ensino. In: RAMA, A.; VERGUEIRO, W. (Orgs.). Como usar as histórias em quadrinhos na sala de aula. São Paulo: Contexto, 2004. p. 7-29.

THAVES, B. Frank e Ernest. O Estado de S. Paulo, São Paulo, 10 jul. 2010. Disponível em:

$<$ http://busca.estadao.com.br/?q=thaves $>$. Acesso em: 3 ago. 2018.

WATTERSON, B. O melhor de Calvin. O Estado de S. Paulo, São Paulo, 7 jul. 2005, p. 4.

WERTHAM, F. Seduction of the innocent. Laurel: Main Road, 2005 [1954].

WILLIAMS, R. M.-C. Image, text, and story: comics and graphic novels in the classroom. Des Moines: Teaching and Learning, 2008.

YANG, G. Graphic novels in the classroom. Language Arts, Atlanta, v. 85, n. 3, 2006, p. 185-192.

Disponível em: http://www.ncte.org/library/NCTEFiles/Resources/Journals/LA/0853-

jan08/LA0853Graphic.pdf. Acesso em: 26 de agost. 2017.

Josiane Brunetti Cani, doctor in Applied Linguistics by the Graduate Program in Linguistic Studies of the Federal University of Minas Gerais (UFMG), Master of Education from Universidad del Norte, Paraguay. Servant of the Federal Institute of Education, Science and Technology of the Holy Spirit and professor of the Faculty Castelo Branco. Member of the Studies and Research group of Ifes: "Language, Literature and Education", with academic interest in issues related to the dialogue between the three articulated axes, offering research perspective with pragmatic developments, especially in the educational area and the research group of the Federal University of Minas Gerais "Free Text: Semiotics and Technology" with highlights for language and technology.E-mail: josicani@gmail.com 